\title{
Dental care associated with an outbreak of HIV infection among dialysis patients ${ }^{1}$
}

\author{
Leonelo E. Bautista ${ }^{2}$ and Myriam Oróstegui ${ }^{3}$
}

\begin{abstract}
An outbreak of 14 cases of human immunodeficiency virus (HIV) infection was discovered by chance in May 1993 among hemodialysis patients at a university hospital in Bucaramanga, Colombia. The outbreak occurred in 1992. Stored sera were used to establish the probable period of infection (PPI) for 10 of the 14 cases. A nested case-control study was carried out to evaluate possible transmission mechanisms. The health care experience of each HIV-positive patient during that patient's PPI was compared to the experience of time-matched controls. Only invasive dental procedures were significantly associated with the risk of infection. Patients upon whom invasive dental procedures were performed during their PPIs had an average risk of HIV infection 8.15 times greater than comparable controls $(\mathrm{P}=0.006)$, and seven out of nine cases of HIV infection with known PPIs in 1992 had an invasive dental procedure performed one to six months before seroconversion. None of the dental care personnel were found to be infected. Based on the available evidence, it seems most likely that the infection was transmitted from patient to patient by contaminated dental instruments.
\end{abstract}

Transmission of human immunodeficiency virus (HIV) during health care is rare. The risk of transmission from an infected patient to a health care worker by percutaneous exposure to infected blood is about three in a thousand (1). The risk of transmission from health care workers to patients should be even lower and has never been adequately documented (2). Nevertheless, patient-to-patient transmis-

\footnotetext{
1 This article will also be published in Spanish in a forthcoming issue of this journal.

2 Industrial University of Santander, School of Medicine, Bucaramanga, Colombia. Mailing address: Universidad Industrial de Santander, Facultad de Salud, Departamento de Salud Pública, Carrera 32, No. 29-31, 3er. piso, Bucaramanga, Colombia.

3 Industrial University of Santander, School of Medicine, Bucaramanga.
}

sion via contaminated equipment has been reported frequently $(3,4)$, and reuse of contaminated needles in Africa has been considered an important HIV transmission mechanism (5).

There are few instances where clusters of HIV infections have been associated with medical care. However, a cluster of HIV-infected dental patients was reported by the U.S. Centers for Disease Control and Prevention (CDC) in $1990(6,7)$. In that instance it was found that patients were infected during dental care, and three possible transmission pathways were identified: from patient to patient by contaminated equipment; from the infected dentist to patients by accidental cuts (blood from the dentist entering the bleeding mouths of patients); and intentional transmission from the infected dentist to patients by an unknown mechanism $(8,9)$. Though the CDC preferred the unintentional dentist-to-patients transmission hypothesis (7), other authors (10-12) felt that the virus could have been transmitted from patient to patient. Unfortunately, there was no direct evidence to support any of these hypotheses (9).

Elsewhere, a cluster of cases of HIV infection transmitted nosocomially in a Russian pediatric hospital was apparently due to reuse of unsterile needles (3). Also, in 1993 two clusters of cases of HIV infection were reported among hemodialysis patients in Argentina (13). Although neither of these Argentine outbreaks have been formally studied and reported in the published literature, it appears that reuse of dialysis filters for different 
patients was the most likely transmission mechanism.

In the work reported here, we studied an outbreak of cases of HIV infection that occurred among chronic hemodialysis patients at a university hospital in Bucaramanga, Colombia, in order to identify possible transmission mechanisms. The outbreak occurred during 1992 and was discovered by chance in May of 1993. Another study of this outbreak has previously been published (14). The present article assesses the validity of that study's findings.

\section{METHODS}

\section{Case-finding}

We searched for cases among all kidney transplant candidates who had used the hemodialysis unit since 1982. As part of the kidney transplant program, blood samples had been collected monthly from these patients, and serum samples had been stored for immunocompatibility tests. The available stored sera and blood samples were tested for HIV antibodies by enzyme-linked immunosorbent assay (ELISA). All ELISA-positive cases were confirmed by western blot, except for one where the western blot results were indeterminate.

To ascertain the time of seroconversion, stored sera from each patient were tested, beginning with the most recent serum and proceeding toward the earliest, until a sample yielded HIV-negative results. The probable period of infection (PPI) for each infected patient was defined as the interval from the date of the patient's most recent HIV-negative serum to the date of that patient's first HIV-positive serum.

We also searched for HIV cases among health care workers in charge of dialysis patients, hemophiliacs using the hospital's blood bank, persons who had donated blood received by the infected patients (if one or more of these donations had occurred anywhere from three months before the start of the patient's PPI to the end of that PPI), and sexual partners of infected patients.

\section{Study design}

Risk factors that were studied included each subject's age, sex, marital status, history of sexually transmitted diseases (STD), frequency of dialysis, and invasive procedures (2) (blood transfusion, kidney transplant, surgery, cystoscopy, gastroscopy, thoracic or lumbar puncture, and dental procedures). The effects of risk factors that did not change during the outbreak (sex, age, marital status, and STD history) were evaluated by means of a retrospective cohort study encompassing all users of the dialysis unit from January 1990 to December 1993. Crude and Mantel-Haenszel adjusted relative risks (15) were calculated.

To explore the effects of the multiple dialyses, transfusions, and invasive procedures, we performed a nested case-control study with incidence density sampling (16). The sampling method permitted selection of one or more unrepeated periods from each patient's history, with each selected period being handled as a separate observation unit during the analysis. Periods within the PPI and before the PPI were considered "case periods" and "control periods," respectively. "Case periods" were obtained only from infected patients, while "control periods" were obtained from both infected patients (before the PPI) and uninfected patients. All available "case periods" with at least one available "control period" of the same duration and calendar time were included in the study. Since all but one patient who underwent dialysis during the mid-1992 outbreak period got infected with HIV, the use of "case periods" and "control periods" was necessary in order to make the data analysis possible.

The duration and calendar times of the "case periods" were defined so as to relate to the available "control periods." All available "control periods" for a matching "case period" were included in the matched set. For exam- ple (see Figure 1), patient 12 contributed two matched sets: His experience during May 1992 was matched with the experience of patients 2 and 5 during the same month; and his experience during his whole PPI (early May to mid-June 1992) was matched with the experience of patient 3 during the same calendar period (Figure 1).

"Case periods" were selected within each infected patient's PPI because events occurring during the PPI were those most likely to have been associated with acquisition of the infection. Thus, events within the case periods constituted the etiologically relevant exposures (17). In contrast, "control periods" were selected from times before the PPI began, and only events occurring during a period of the same length and calendar time as the matching patient's "case period" were considered relevant exposures.

Conditional logistic regression (18) was used for data analysis; no study variables were excluded from the regression model because all of them were deemed to be potential risk factors. Since the periods contributed by a patient could be nonindependent, we used random effect binomial logistic regression (19) to account for this possibility and to obtain valid statistical tests and confidence intervals. Pregibon's delta-beta statistics were calculated to evaluate the influence of each observation upon the study results (20).

\section{RESULTS}

The unit, which had seven dialysis machines, treated an average of 10 patients daily. The patients followed one of three treatment patternsreceiving dialysis on Monday, Wednesday, and Friday; Tuesday and Friday; or Monday and Thursday. During 1990-1993 the unit cared for 49 chronic dialysis patients. Only 35 of them had at least one stored serum sample or were available for blood sampling when the HIV outbreak was detected. All the other patients had died or had received a successful kidney transplant. At the time the out- 
FIGURE 1. Results of serologic follow-up of patients undergoing dialysis at the study hospital from April 1991 through August 1993

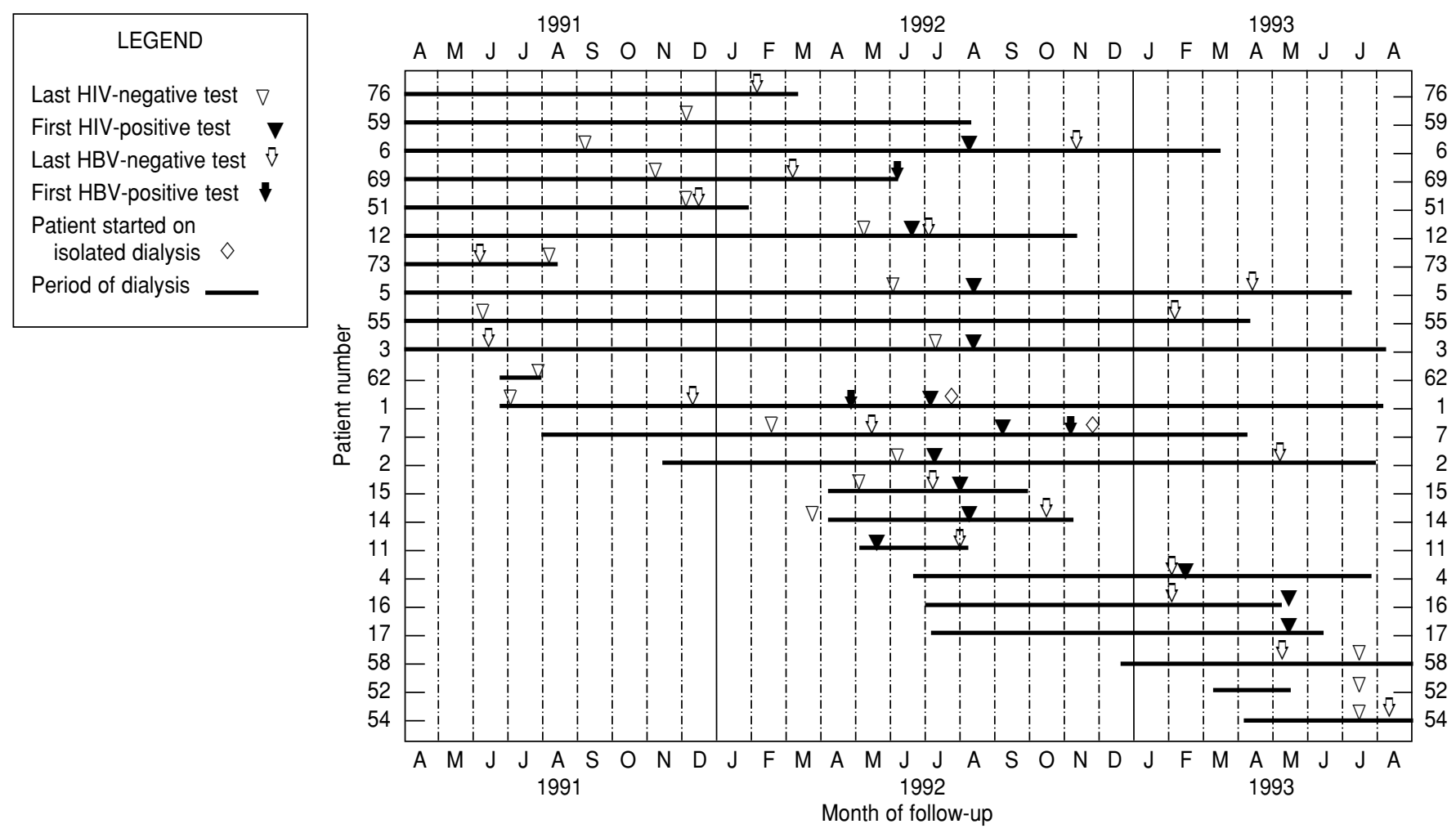

break was detected, $14(40 \%)$ of the 35 patients with available serum samples were found to be HIV-infected.

One patient was identified as seropositive for the first time using a sample from 1990, 10 were so identified using samples from 1992, and three were so identified using samples from 1993 (Table 1). The duration of the PPI was determined in 10 cases and was found to vary from 1 to 12 months, with a median of 3 months. It is likely that the PPI's duration was overestimated for three patients with PPIs longer than six months, because each of these patients had only one stored serum sample predating their first HIV-positive serum. The duration of the PPI could not be established for four patients because they had no available serum samples predating the first HIV-positive sample.

Of the nine patients whose PPIs could be defined and were known to have occurred in 1992, three had their first positive HIV test in July 1992 and four had it the following month (Table
2 and Figure 1). By the end of 1992, 10 patients who received dialysis that year had become infected; one patient who started dialysis in December 1992 showed no serologic evidence of infec-

tion; and the HIV status of three others who became HIV-positive in 1993 was unknown. One patient started dialysis in March 1993 and another started it the following month. At the

TABLE 1. Date of detection of HIV infection and duration of the probable period of infection (PPI) for each case studied, 1990-1993

\begin{tabular}{rccc}
\hline $\begin{array}{c}\text { Case } \\
\text { number }\end{array}$ & $\begin{array}{c}\text { Date of } \\
\text { last negative } \\
\text { HIV test }\end{array}$ & $\begin{array}{c}\text { Date of } \\
\text { first positive } \\
\text { HIV test }\end{array}$ & $\begin{array}{c}\text { Duration } \\
\text { of PPI } \\
\text { (months) }\end{array}$ \\
\hline 8 & 25 Jan 1990 & 15 May 1990 & 3.6 \\
12 & 12 May 1992 & 23 Jun 1992 & 1.4 \\
1 & 2 Jul 1991 & 3 Jul 1992 & 12.0 \\
2 & 4 Jun 1992 & 9 Jul 1992 & 1.1 \\
15 & 4 May 1992 & 27 Jul 1992 & 2.8 \\
14 & 27 Mar 1992 & 2 Aug 1992 & 4.2 \\
6 & 2 Sep 1991 & 4 Aug 1992 & 11.0 \\
3 & 7 Jul 1992 & 5 Aug 1992 & 1.0 \\
5 & 4 Jun 1992 & 10 Aug 1992 & 2.2 \\
7 & 7 Feb 1992 & 2 Sep 1992 & 6.8 \\
$11^{\text {a }}$ & - & 18 May 1992 & - \\
$16^{\mathrm{a}}$ & - & 17 May 1993 & - \\
$17^{\mathrm{a}}$ & - & 13 May 1993 & - \\
$4^{\mathrm{a}}$ & - & 12 Feb 1993 & - \\
\hline
\end{tabular}

${ }^{a}$ No HIV-negative serum available. 
TABLE 2. Number of dialysis patients in 1992, number of patients at risk of HIV infection (total minus HIV-positive patients), and number and percent of at-risk patients who became infected, by month

\begin{tabular}{|c|c|c|c|c|c|c|c|}
\hline \multirow[b]{2}{*}{ Month } & \multicolumn{2}{|c|}{ Patients } & \multicolumn{2}{|c|}{ HIV status } & \multicolumn{2}{|c|}{1992 cases } & \multirow[b]{2}{*}{ Risk (\%) } \\
\hline & Total & At risk & Positive $^{a}$ & Unknown & New & Cumulative $^{b}$ & \\
\hline January & 11 & 8 & $3^{c}$ & 0 & 0 & 0 & 0.0 \\
\hline February & 10 & 8 & 2 & 0 & 0 & 0 & 0.0 \\
\hline March & 10 & 8 & 2 & 0 & 0 & 0 & 0.0 \\
\hline April & 11 & 9 & 2 & 0 & 0 & 0 & 0.0 \\
\hline May & 13 & 10 & 3 & 0 & 0 & 1 & 0.0 \\
\hline June & 13 & 9 & 3 & 1 & 1 & 2 & 11.1 \\
\hline July & 14 & 8 & 4 & 2 & 3 & 5 & 37.5 \\
\hline August & 11 & 5 & 4 & 2 & 4 & 9 & 80.0 \\
\hline September & 11 & 1 & 3 & 7 & 1 & 10 & 100.0 \\
\hline October & 10 & 1 & 3 & 6 & 0 & 10 & 0.0 \\
\hline November & 11 & 1 & 3 & 7 & 0 & 10 & 0.0 \\
\hline December & 9 & 1 & 3 & 5 & 0 & 10 & 0.0 \\
\hline
\end{tabular}

a Still in dialysis.

${ }^{\mathrm{b}}$ Accumulated during 1992.

c One patient was infected in 1988 and two in 1990.

time the outbreak was detected (in May 1993), neither of them was infected (Figure 1). By the end of 1993, seven $(50 \%)$ of the 14 infected patients and $13(61.9 \%)$ of the 21 uninfected dialysis patients shown in Table 3 had died (two-tailed Fisher exact test, $P=$ 0.511).

An additional infected patient was identified during the retrospective analysis of serum samples. This patient, who was already infected upon entry into the dialysis program in 1988, was excluded from the analysis because the infection occurred too early to be related to the outbreak.

Patient 11 provided the earliest HIV-positive serum sample found to be HIV-infected in 1992. The positive sample was collected two weeks after the patient started hemodialysis. The patient underwent only one invasive dental procedure, and this occurred six weeks after starting hemodialysis-at which time he was already HIV-positive.

At the time the outbreak was detected in May 1993, five of the infected patients had already died. Three of the nine survivors reported having no regular sexual partner, while each of the remaining six reported having one. Only one of these six sexual partners tested positive for HIV. No additional cases of HIV infection were found among 100 health care workers who were tested or among 26 hemophiliacs who regularly used the hospital blood bank. Twenty-one of the 56 people who donated blood to the infected patients were located and tested, but none of them was found to be HIV-positive.

Fifteen $(42.9 \%)$ of the original 35 patients received a kidney transplant before or during 1993. While two out of six HIV-positive patients who received transplants tested HIV-negative before the transplant, their kidney donors were also HIV seronegative.

Crude and adjusted analyses of the retrospective cohort study showed that the risk of infection was not significantly associated with age, sex, or marital status ( $P$ values of two-tailed Fisher exact test: sex $=0.09$, age $=0.95$, and marital status $=0.40$; see Table 3 data). In contrast, all four patients with a history of STD were found to be HIV-positive, as compared to only 10 $(32.2 \%)$ of the 21 patients without a history of STD (two-tailed Fisher exact test: $P=0.02$ ).

The nested case-control study included data from infected patients with known PPI and from one uninfected patient. One or more "control periods" were identified for all "case periods" except for those "case periods" contributed by patient 3 (see Figure 1). In all, we compared 34 "case periods" provided by eight infected patients $(12,1,2,15,14,6,5$, and 7 ; see Table 1) to 51 "control periods" supplied by the uninfected patient and 10 other patients before the start of their PPIs $(59,6,69,51,12,5,3,62,7,2$, and 15; see Figure 1).

Patients who had endoscopies or other invasive procedures (aside from dental procedures) were not found to have a greater risk of HIV infection,

TABLE 3. Risk of HIV infection by sex and age among dialysis patients at the study hospital, 1990-1993

\begin{tabular}{|c|c|c|c|c|c|c|c|c|c|}
\hline \multirow[b]{2}{*}{$\begin{array}{c}\text { Age } \\
\text { (years) }\end{array}$} & \multicolumn{3}{|c|}{ Men } & \multicolumn{3}{|c|}{ Women } & \multicolumn{3}{|c|}{ Total } \\
\hline & $\begin{array}{c}\text { No. of } \\
\text { patients }\end{array}$ & $\begin{array}{l}\text { No. of } \\
\text { HIV cases }\end{array}$ & $\begin{array}{l}\text { Risk } \\
(\%)\end{array}$ & $\begin{array}{c}\text { No. of } \\
\text { patients }\end{array}$ & $\begin{array}{l}\text { No. of } \\
\text { HIV cases }\end{array}$ & $\begin{array}{l}\text { Risk } \\
(\%)\end{array}$ & $\begin{array}{c}\text { No. of } \\
\text { patients }\end{array}$ & $\begin{array}{l}\text { No. of } \\
\text { HIV cases }\end{array}$ & $\begin{array}{l}\text { Risk } \\
(\%)\end{array}$ \\
\hline $20-29$ & 3 & 2 & 66.7 & 2 & 0 & 0.0 & 5 & 2 & 40.0 \\
\hline $30-39$ & 6 & 3 & 50.0 & 5 & 2 & 40.0 & 11 & 5 & 45.4 \\
\hline $40-49$ & 10 & 5 & 50.0 & 3 & 0 & 0.0 & 13 & 5 & 38.5 \\
\hline
\end{tabular}

Two-tailed Fisher exact test $P$ values: $\operatorname{sex}=0.09$, age $=0.95$, marital status $=0.40$, history of $\mathrm{STD}=0.02$. 
even after adjusting for other variables (Table 4). Neither were blood transfusion or hemodialysis associated with a significantly increased risk of HIV infection. Other potential risk factors such as surgery were too rare among those affected to have served as the principal transmission vehicle.

Of all the risk factors studied, only invasive dental procedures (IDP) were significantly associated with HIV infection in both the crude and adjusted analyses (see Table 4). Indeed, the adjusted risk of HIV infection was 8.15 times higher for patients who had IDP during their PPI than for those who had not $(95 \%$ confidence interval: 1.85-36.0); and it almost tripled for each IDP (odds ratio: 2.98; 95\% CI: 1.21-7.36). These results did not change with random effects logistic regression analysis (19), and the random intercept was not statistically significant $(P=0.311)$.

The average number of invasive dental procedures performed on the study subjects was 1.73 during "case periods" and 0.36 during "control periods." Of the eight patients who contributed "case periods," five had invasive dental procedures performed during their PPIs, while only two of the eleven who contributed "control periods" had such procedures performed during these control periods (two-tailed Fisher exact test: $P=0.07)$. Of the ten HIV-positive patients with known PPIs, the one patient who tested positive in 1990 never had an invasive dental procedure and probably had no connection with the 1992 outbreak. However, eight of the nine patients testing HIV-positive for the first time in 1992 had experienced an invasive dental procedure 1-6 months before seroconversion (in seven cases) or 21 months before seroconversion (in the eighth case). In this group, the median time elapsing between the dental procedure and the first HIV-positive sample was 3.5 months. No invasive dental procedure was reported for one of the nine patients testing HIV-positive in 1992.

We investigated the times when the infected patients were given invasive dental procedures in order to identify possible chains of transmission within the dental unit. We only found three patients who received dental care the same day (all before their first HIV-positive test) and two others who received care one day apart (one uninfected and the other with unknown HIV status). These data did not permit identification of a chain of transmission.

Preliminary data from study of the HIV genome indicate that the nucleotide sequences obtained from variable and constant regions of the glycoprotein gp120 were more similar among viruses taken from outbreak-infected patients than they were among viruses taken from a control group (21).

\section{DISCUSSION}

Our results indicate that invasive dental procedures provided the most likely mechanism for HIV transmission during this outbreak. Although a history of STD was strongly associated with higher risk of HIV infection, none of the infected patients had a sexually transmitted disease during 1992, none reported more than one sexual partner, and only one of the six reported sexual partners tested positive for HIV. These findings suggest that the observed association between STD and HIV infection was due to chance.

Neither is it likely that HIVcontaminated blood transfusions were the source of infection. Blood banks in the city have practiced HIV screening since 1988; the number of transfusions was similar in "case" and "control" periods; and no infected person was found among people who donated blood received by the infected patients or among hemophiliacs who used the hospital blood bank regularly.

The number of dialyses received by the study subjects was not associated with the risk of HIV infection. Although other authors (14) have argued that this outbreak was caused by interchange of contaminated access needles, we found no evidence to support that hypothesis. Indeed, these findings seem questionable because the authors compared patients who used the dialysis unit during the outbreak with patients who used it before the outbreak. Also, they defined exposures based on HIV infection status and provided no evidence of association between needle interchange and risk of infection. Since needles were

TABLE 4. Crude and adjusted odds ratios for risk factors of HIV infection, 1992

\begin{tabular}{|c|c|c|c|c|c|c|}
\hline \multirow{2}{*}{$\begin{array}{l}\text { Risk } \\
\text { factor }\end{array}$} & \multicolumn{3}{|c|}{ Crude odds ratio } & \multicolumn{3}{|c|}{ Adjusted odds ratio ${ }^{a}$} \\
\hline & Odds ratio & $95 \% \mathrm{Cl}^{\mathrm{b}}$ & $P^{c}$ & Odds ratio & $95 \% \mathrm{Cl}^{\mathrm{b}}$ & $P^{c}$ \\
\hline Cystoscopy & 2.11 & $0.46-9.79$ & 0.34 & 1.47 & $0.23-9.26$ & 0.68 \\
\hline Gastroscopy & 2.12 & $0.68-6.62$ & 0.20 & 1.21 & $0.25-9.26$ & 0.81 \\
\hline Other nondental invasive procedures ${ }^{d}$ & 2.16 & $0.20-23.88$ & 0.53 & 1.36 & $0.10-17.98$ & 0.82 \\
\hline Blood transfusions & 1.05 & $0.35-3.15$ & 0.94 & 1.31 & $0.35-4.94$ & 0.69 \\
\hline Hemodialysis & 1.01 & $0.99-1.02$ & 0.52 & 0.99 & $0.96-1.01$ & 0.36 \\
\hline Invasive dental procedures & 6.36 & $1.97-20.51$ & 0.002 & 8.15 & $1.85-36.0$ & 0.006 \\
\hline
\end{tabular}

adjusted for the variables in the table.

${ }^{\mathrm{b}} \mathrm{Cl}=$ confidence interval.

c Wald's test $P$ values.

${ }^{d}$ Including thoracic and lumbar punctures. 
stored in pans labeled with the patients' names and new needles were used every Monday, needle interchange was unlikely; nor was HIV survival within the dialysis needles likely, because the needles were soaked in a $0.16 \%$ benzalkonium chloride solution for at least 48 hours $(22,23)$.

Because dialysis filters and lines were used individually, were cleaned thoroughly with saline solution after use, and were filled with a 5\% formaldehyde solution for 24-48 hours before reuse, transmission by these means seems unlikely. Transmission through the dialysis machines themselves is not possible because the machines do not come in direct contact with the patient's blood.

Also, during 1988 and 1990 two HIV-infected patients were regularly dialyzed without knowledge of their HIV status. Despite the fact that the personnel and equipment processing procedures were the same as in 1992, there were no apparent HIV outbreaks during those years. This supports the theory that dialysis was not responsible for the HIV transmission.

Neither does the history of hepatitis $B$ virus (HBV) infection among the study patients point to transmission within the dialysis unit. Patients were tested for HBV every three months. Patients 1 and 7 became infected with HBV in 1992, and consequently started dialysis with separate equipment. By that time they were already HIV-positive (Figure 1). Though patient 69 was also HBV positive, he was so identified through a blood sample drawn the day after his last dialysis. In all, these three patients received at least 47 dialyses on equipment shared by other patients after becoming HBV positive. Even though $\mathrm{HBV}$ is much more infective than HIV $(2,24)$, only three out of 14 patients got infected with HBV, compared to nine out of 10 infected with HIV. Thus, the absence of an HBV outbreak indicates that dialysis was not the vehicle responsible for the much more extensive HIV transmission among the study subjects.

Though many invasive procedures afford potential means of HIV trans- mission (2), none except dental procedures were significantly associated with the risk of HIV infection. Additional facts supporting dental transmission: Patients 52, 54, and 58 (Figure 1) and four chronic ambulatory peritoneal dialysis patients were the only 1992 kidney transplant candidates who did not get infected with HIV. They never received an invasive dental procedure. Also, patient 14 (who never reused dialysis equipment) and patient 10 (who was never dialyzed in the unit) were treated with an invasive dental procedure 2-4 months before their HIV seroconversions. Finally, all but one of the patients infected in 1992 received an invasive dental procedure before seroconversion. This lone 1992 seroconverter had no history of STD. Since all kidney transplant candidates had to have at least one dental evaluation, the absence of any dental report for this patient suggests that part of the patient's clinical record was missing.

The high risk of infection and the shortness of the PPIs suggest that the HIV was transmitted by blood. Since none of the dental care workers were infected and the infected patients seemed to share the same HIV strain, patient-to-patient transmission by means of contaminated dental instruments was the most likely form of contagion. However, due to the overlapping of the PPIs, it was not possible to identify an index case. Since the dental service cared for other patients, the possibility of a nondialysis patient having been the index case cannot be ruled out.

The absence of a clear chain of transmission within the dental unit could be due to several circumstances. First, a patient's true date of infection depends upon when the patient acquired HIV rather than when he provided the stored blood sample yielding HIVpositive results. This makes it hard to define any progressive sequence of HIV transmissions with certainty. Second, there were no stored sera from patients who had died or had received a successful kidney transplant. Third, we cannot rule out the possibility that other dental patients (such as hospital inpatients other than the kidney transplant candidates and hospital outpatients, for whom no data were available) could have been links in the chain of transmission.

Transmission of HIV by contaminated dental instruments is plausible because HIV is present in the blood, saliva (25), and dental pulp (26) of infected patients. Around the end of 1991, the dental service started providing care for HIV-positive patients referred by the League Against AIDS. This could have triggered the outbreak of HIV infections among dialysis patients. In September of 1992 dental personnel refused to provide care for HIV-infected patients because the dental service did not have the necessary resources.

Our results seem unlikely to be biased. Only patients with unknown PPI were excluded from the study. It appears unlikely that their not having provided stored serum samples would have been associated with whether or not they received invasive dental procedures or their HIV infection status. Confounding factors were controlled by multiple regression and by getting "case periods" and "control periods" from the same patients. Other potential risk factors-such as use of injected drugs, tattooing, and other skin penetration procedures-were rare in the study population and were not reported by interviewed survivors. None of the male patients admitted to having had homosexual contacts. Since the study patients' clinical records were completed without knowledge of their HIV-positive status, recording errors should be nondifferential and could if anything have attenuated the association between invasive dental procedures and HIV infection (27).

It is reasonable to argue that if HBVinfected patients had IDP there should have been a higher HBV infection rate among dialysis patients. However, except for one HBV-infected patient who had three IDP, no other HBVinfected patients had IDP during the outbreak period. Thus, the chance for transmission of HBV through IDP was low. 
By considering as etiologically relevant just the exposure during the PPI, we could have omitted relevant events occurring before the last HIVnegative test if the test result was a false negative. This could have happened if the patient was in the immunologic window phase. Nevertheless, due to the high sensitivity of the ELISA for HIV, the likelihood of a false negative result was very small. In any case, errors due to false negative tests should be nondifferential and would have diluted the estimated effect of IDP. Similarly, since clinical records were filled out without knowledge of the patients' HIV status, recording errors should be nondifferential and could in fact have attenuated the association between IDP and HIV infection $(17,27)$.

Though we have no direct evidence, HIV could have been transmitted to the study subjects by contaminated handpieces or prophylaxis angles (low-speed handpieces used for cleaning and polishing teeth) (28), incorrect use of the saliva ejector (29), or inadequately sterilized surgical instruments. Experimental studies (28, 30-33) have shown that turbines and water lines in handpieces and prophylaxis angles can get contaminated with a patient's oral fluids during regular use. Such contamination is apt to be particularly heavy in dental units where antiretraction valves are absent or defective $(28,34,35)$. Lewis et al. (28) have recovered infective particles from a bacteriophage, HIV, and HBV DNA from inside handpieces and prophylaxis angles used on infected patients. It seems clear, therefore, that if these instruments are not adequately treated, microorganisms from one patient could enter the mouth of the next.

Handpiece sterilization by autoclaving between patients is currently recommended $(36,37)$; but most handpieces and prophylaxis angles cannot resist the accompanying heat, nor can they be treated with concentrated internal and external disinfectants (30, $35,36)$. Therefore, their treatment consists mainly of external cleaning with a disinfectant solution. Since external cleaning does not solve the problem of turbine and water-line contamination $(30,32,35)$, the U.S. Centers for Disease Control and Prevention (CDC) recommend running the handpiece and discharging water into a sink for $20-30$ seconds between patients. However, there is evidence that this recommended flushing time may be too short (30).

Incorrect use of the saliva ejector could also result in cross-infections (29). A backflow of fluids into the patient's mouth can occur when the patient's lips close around the tip of the ejector. In that event, changing the saliva ejector tip is not sufficient to prevent cross-contamination between patients (29).

When the outbreak studied here occurred, the dental service did not have written infection control standards. Dry heat was used for sterilizing dental equipment; but sterilization ovens did not have thermometers, nor was biological monitoring (sporetesting) carried out. Moreover, dental units did not have antiretraction valves; handpieces and prophylaxis angles were not sterilizable; and the saliva ejector tip, which was not discardable, was cleaned between patients with an alcohol solution.

In July 1990 the $\operatorname{CDC}(6,7)$ reported the first case of HIV infection associated with dental care. Though the transmission mechanism was not established $(8,9)$, several investigators (10-12) think the virus could have been transmitted from patient to patient by contaminated equipment. Despite the potential for such transmission of blood-borne diseases during dental care, there have been no published studies on the subject. This is probably due to three factors: The studies of HIV outbreaks associated with dental care have focused on dentist-to-patient transmission $(2,30)$; there are no efficient surveillance systems to detect and report crossinfections associated with dental care; and HIV and HBV infections have traditionally been attributed to the bestknown risk factors $(30,32)$.

After detection of the outbreak described here, infection control mea- sures were enforced in all the hospital's services. Reuse of dialysis filters and needles was suspended, as was the kidney transplant program. Due to the program's suspension, kidney transplant candidates were no longer required to undergo dental procedures to eradicate potential sources of infection. Though no new infections occurred among dialysis patients after May 1993, we could not rule out the possibility that other cases occurred among other hospital patients for whom there were no stored sera. The risk of infection among these latter patients could have been lower than the risk among kidney transplant candidates-who undergo all types of dental care procedures needed to eradicate potential sources of infection. Such thorough dental care is not customary for other patients.

Study of the patients who used the dental unit in 1992 could have helped clarify our findings. However, dental care records were very poor. Using the dental unit's records, only one of the patients involved in this outbreak was identified as receiving dental care in 1992. Fortunately, kidney transplant candidates had dental care histories included in their clinical records-because this information was needed in order to decide whether the patient was ready to receive a transplant. Similar records were not kept for other hospital patients. Discovery of the outbreak a considerable time (one year) after its occurrence made it particularly hard to locate previous users of the dental unit. The only reasonable option for identifying potentially infected users of the dental unit was by public request, a procedure not allowed by local health authorities.

Our results point to a form of HIV transmission not reported previously. Even in developed countries, crossinfection control during dental care has been considered deficient $(29,30$, $32,38)$. This strongly suggests that in developing countries dental care could be associated with HIV and other viral cross-infections and could constitute an important means of blood-borne disease dissemination. 


\section{REFERENCES}

1. Henderson DK, Fahey BJ, Willy $\mathrm{M}$, et al. Risk for occupational transmission of human immunodeficiency virus type 1 (HIV1) associated with clinical exposures: a prospective evaluation. Ann Intern Med 1990; 113:740-746.

2. Centers for Disease Control. Recommendations for preventing transmission of human immunodeficiency virus and hepatitis B virus to patients during exposure-prone invasive procedures. MMWR 1991;40(RR-8):1-9.

3. Pokrovskii VV, Eramova II, Deulina MO, et al. [An intrahospital outbreak of HIV infection in Elista]. Zh Mikrobiol Epidemiol Immunobiol 1990;4:17-23. (Russian).

4. Patrascu IV, Dumitrescu O. The epidemic of human immunodeficiency virus infection in Romanian children. AIDS Res Hum Retroviruses 1993;9:99-104.

5. Quinn TC, Mann JM, Curran JW, Piot P. AIDS in Africa: an epidemiologic paradigm. Science 1986;234:955-963.

6. Centers for Disease Control. Possible transmission of human immunodeficiency virus to a patient during an invasive dental procedure. MMWR 1990;39:489-493.

7. Ciesielski C, Marianos D, Ou CY, et al. Transmission of human immunodeficiency virus in a dental practice [see comments]. Ann Intern Med 1992;116:798-805.

8. Robinson $\mathrm{P}$, Challacombe S. Transmission of HIV in a dental practice: the facts. $\mathrm{Br}$ Dent $\mathrm{J}$ 1993;175:383-384.

9. Breo DL. The dental AIDS cases: murder or an unsolvable mystery? JAMA 1993;270(22): 2732-2734.

10. Taylor F. The risk of transmission of HIV from health care professionals to patient [letter]. JAMA 1991;266(14):1935.

11. Barondes JA. The risk of transmission of HIV from health care professional to patient [letter]. JAMA 1991;266(14):1936

12. Stark AN. Cross-contamination with dental equipment [letter; comment]. Lancet 1993; 341:180.

13. Dyer E. Argentinian doctors accused of spreading AIDS. Br Med J 1993;307:584.
14. Velandia M, Fridkin SK, Cardenas V, et al. Transmission of HIV in dialysis centre. Lancet 1995;345:1417-1422.

15. Mantel N, Haenszel W. Statistical aspects of the analysis of data from retrospective studies of disease. I Natl Cancer Inst 1959;22:719-748.

16. Checkoway H, Pearce N, Crawford-Brown DJ. Case control studies: anonymous research methods in occupational epidemiology. New York: Oxford University Press; 1989:170-201.

17. Rothman K. Induction and latent periods. $A m$ J Epidemiol 1981;114(2):253-259.

18. Hosmer DW, Lemeshow S. Applied logistic regression. New York: Wiley; 1989.

19. Statistics and Epidemiology Research Corporation. EGRET, program manual. Seattle: Statistics and Epidemiology Research Corporation; 1990:265-282.

20. Pregibon D. Logistic regression diagnostics. Ann Stat 1981;9:705-724.

21. Rengito B, Boshell J, Essex M, et al. Epidemilogía molecular de una infección por el virus de la inmunodeficiencia humana en un hospital universitario colombiano. Resúmenes del VII Congreso Panamericano de Infectología, Cartagena, Colombia, Mayo 26-31, 1995. Cartagena: Asociación Panamericana de Infectología; 1995

22. Resnick L, Veren K, Salahuddin S, Tondreau S, Markham PD. Stability and inactivation of HTLV-III/LAV under clinical and laboratory environments. JAMA 1986;255(14):1887-1891.

23. Sattar SA, Springthorpe VS. Survival and disinfectant inactivation of the human immunodeficiency virus: a critical review. Rev Infect Dis 1991;13:430-447.

24. Gerberding JL. Reducing occupational risk of HIV infection. Hosp Pract 1991;26:103-118.

25. Chamberland ME, Curran JW. Epidemiology and prevention of AIDS and HIV infection. In: Mandell GL, Douglas RG Jr, Bennett JE. Principles and practice of infectious diseases. 3rd ed. New York: Churchill Livingstone; 1990: 1029-1046.

26. Glick M, Trope M, Pliskin ME. Detection of HIV in the dental pulp of a patient with AIDS. I Am Dent Assoc 1989;119(5):649-650.
27. Copeland KT, Checkoway H, McMichael AJ Holbrook RH. Bias due to misclassification in the estimation of relative risk. Am J Epidemiol 1977;105(5):488-495.

28. Lewis DL, Arens M, Appleton SS, et al. Crosscontamination potential with dental equipment [comment]. Lancet 1992;340:1252-1254.

29. Watson CM, Whitehouse RL. Possibility of cross-contamination between dental patients by means of the saliva ejector. J Am Dent Assoc 1993;124:77-80.

30. Lewis DL, Boe RK. Cross-infection risks associated with current procedures for using highspeed dental handpieces [comments]. J Clin Microbiol. 1992;30:401-406.

31. Mills SE, Kuehne JC, Bradley DV. Bacteriological analysis of high-speed handpiece turbines. I Am Dent Assoc 1993;124:59-62.

32. Lewis DL. Infection control in dental handpieces [letter]. ASM News 1991;57(8):393.

33. Shpuntoff H, Shpuntoff RL. High-speed dental handpieces and spread of airborne infections [see comments]. N Y State Dent J 1993; 59:21-23.

34. Singh B, Bagga R, Murphy RA, Punwani I. Contamination of dental unit cooling water with oral microorganisms and its prevention J Am Dent Assoc 1984;109:712-716.

35. Miller $\mathrm{CH}$. Cleaning, sterilization and disinfection: basics of microbial killing for infection control. J Am Dent Assoc 1993;124:48-56.

36. Sterilizing dental handpieces: results of a workshop on handpieces and other instruments in dentistry. I Am Dent Assoc 1992 123:44-47.

37. British Dental Association. Guidelines on infection control in dentistry: a practitioner's guide. London: BDA; 1993.

38. Nash KD. How infection control procedures are affecting dental practice today. I Am Dent Assoc 1992;123:67-73.

Manuscript received on 3 April 1996. Revised version accepted for publication on 9 October 1996 
RESUMEN En mayo de 1993 se descubrió fortuitamente un brote de 14 casos de infección por virus de la inmunodeficiencia humana (VIH) en pacientes sometidos a hemodiálisis en un hospital universitario de Bucaramanga, Colombia. El brote tuvo lugar en 1992.

\section{Atención dental asociada con un brote de infección por VIH en pacientes sometidos a diálisis} Se usaron sueros almacenados para determinar el período de infección probable (PI) de 10 de los 14 casos y se llevó a cabo un estudio de casos y controles anidado a fin de evaluar los posibles mecanismos de transmisión. La atención de salud recibida por cada paciente positivo a VIH durante su PIP se comparó con la atención recibida por controles apareados con los casos en tiempo. Solamente los procedimientos odontológicos invasores mostraron una asociación significativa con el riesgo de infección. Los pacientes sometidos a procedimientos dentales invasores durante su PIP tuvieron un riesgo promedio de infección 8,15 veces mayor que los controles de características similares $(P=0,006)$, y de nueve casos de infección por VIH con un PIP conocido en 1992, siete habían sido sometidos a un procedimiento dental invasor de 1 a 6 meses antes de la seroconversión. No se detectó infección en ninguno de los miembros del personal de salud dental. A juzgar por las pruebas disponibles, es más probable que la infección haya sido transmitida de un paciente a otro por instrumentos dentales contaminados.

\section{Premio Abraham Horwitz en Salud Interamericana, 1997}

La Fundación Panamericana de la Salud y Educación (PAHEF) notifica que, de acuerdo con las recomendaciones de la Junta Directiva, el Premio Abraham Horwitz en Salud Interamericana para 1997 se adjudicará al doctor Gabriel Velázquez Palau, de Colombia. El doctor Palau se ha hecho acreedor a este galardón con sus muchos años de trabajo que han contribuido de manera importante al progreso de la educación médica en América Latina.

El Premio, que honra la larga y fructífera carrera del doctor Abraham Horwitz, Director Emérito de la OPS, está dedicado a estimular la excelencia y el liderazgo en el campo de la salud de las Américas. El doctor Velázquez Palau lo recibirá en el mes de septiembre de 1997, durante la XL Reunión del Consejo Directivo de la OPS. 